\title{
Effect of Helicobacter pylori eradication on peptic ulcer healing
}

\author{
Humphrey J O’Connor, Chakravarthy Kanduru, Abdul S Bhutta, Judith M Meehan, \\ Kenneth M Feeley, Kevin Cunnane
}

\begin{abstract}
Summary
In a prospective study designed to assess the effect of Helicobacter pylori eradication on peptic ulcer healing, 85 consecutive patients with $H$. pylori-positive peptic ulcer disease were treated with a triple therapy regimen consisting of colloidal bismuth subcitrate $120 \mathrm{mg}$ four times daily for 28 days, with metronidazole $400 \mathrm{mg}$ three times daily and tetracycline $500 \mathrm{mg}$ three times daily for the first seven days of treatment. $H$. pylori status was assessed by CLO test ${ }^{\circledR}$ and histology at least four weeks after completing therapy. Of 75 patients $(88 \%) H$. pylori-negative after therapy, 69 (92\%) had healed ulcers compared with only five of 10 patients $(50 \%)$ who remained $H$. pylori-positive $(p=0.003)$. Cigarette smoking had no significant effect on ulcer healing. Our results suggest that $H$. pylori eradication may accelerate ulcer healing and provide further evidence that an effective helicobactericidal regimen is the treatment of choice in $\mathrm{H}$. pylori-positive peptic ulcer.
\end{abstract}

Keywords: Helicobacter pylori, peptic ulcer

\section{Introduction}

The rediscovery of Helicobacter pylori has provoked a fundamental reevaluation of ideas on the aetiology and management of peptic ulcer. Perhaps the strongest evidence linking $H$. pylori and peptic ulcer is the fact that eradication of infection prevents ulcer relapse, effectively curing the disease. This seminal finding was first highlighted by Coghlan et al. ${ }^{1}$ Subsequent studies continued to focus on the effect of $H$. pylori eradication on ulcer relapse $^{2-4}$ with less attention being paid to possible effects on ulcer healing. This prospective study was primarily designed to assess the effect of $H$. pylori eradication on peptic ulcer healing. A secondary aim of the study was to assess the impact of smoking and other factors on ulcer healing and $H$. pylori eradication.

\section{Patients and methods}

PATIENTS

Patients were eligible for inclusion in the study if they were over 18 years of age, in good general health, were found to have a gastric or duodenal ulcer at endoscopy, and had a gastric biopsy which gave a positive rapid urease test indicating the presence of $H$. pylori infection. An ulcer was defined as a circumscribed break in the mucosa measuring at least $5 \mathrm{~mm}$ in the longest diameter with apparent depth and covered with an exudate.

Patients were excluded if they had taken antibiotics or omeprazole in the preceding four weeks, bismuth-containing medication in the preceding three months, were on nonsteroidal anti-inflammatory drugs, had undergone peptic ulcer surgery, were pregnant, or had significant pathology at endoscopy other than gastric or duodenal ulcer. Prior to endoscopy, patients were questioned regarding current and past cigarette smoking. Ex-smokers were considered as nonsmokers for purposes of anlysis in the study. All patients gave written informed consent for endoscopy and inclusion in the study.

\section{ENDOSCOPY AND BIOPSIES}

All the examinations were performed using an Olympus GIFIT 20 endoscope. If after inspection of the oesophagus, stomach, and duodenum, the patient was still considered eligible for inclusion in the study, three mucosal biopsy specimens were obtained using a standard biopsy forceps from the gastric antrum within $5 \mathrm{~cm}$ of the pylorus. One of the biopsy specimens was tested immediately for the presence of preformed urease activity using the CLO test $^{\circledR}$ (Deltawest, Perth, Australia). ${ }^{5}$ The remaining two specimens were fixed in $10 \%$ buffered formaldehyde, coded, and sent for histological evaluation.

Paraffin-processed histological sections were stained with haematoxylin and eosin and by a modified Giemsa stain method, and examined by an experienced pathologist blind to the clinical details and biopsy site. The modified Giemsa-stained sections were specifically examined for the presence of $H$. pylori, detected by the finding of characteristic curved bacilli on the mucosal surface.

\section{THERAPY}

Patients received a triple therapy regimen (see box). All medications were taken before meals.

Patients were counselled prior to starting therapy regarding the possibility of treatmentrelated gastrointestinal side-effects (nausea, taste disturbance, blackening of the stools), 


\begin{tabular}{|l|}
\hline Triple therapy regime \\
\hline - colloidal bismuth subcitrate ( $120 \mathrm{mg}$ qid for \\
28 days) \\
- metronidazole ( $400 \mathrm{mg}$ tid for 7 days) \\
- tetracycline ( $500 \mathrm{mg}$ tid for 7 days) \\
\hline
\end{tabular}

specifically advised to abstain from alcohol for the first week of therapy, and the importance of good compliance to the success of therapy was emphasised.

Repeat endoscopy to assess ulcer healing and $H$. pylori eradication was performed at least four weeks after completing therapy and at that time, patients were questioned regarding compliance and side-effects. Ulcer healing was defined as complete re-epithelialisation. $H$. pylori eradication was defined as the inability to detect evidence of infection on both the CLO test and histological evaluation.

\section{STATISTICS}

Differences in ulcer healing and $H$. pylori eradication between patient groups were tested for statistical significance using two-tailed Fisher's exact test. A p-value $<0.05$ was considered significant.

\section{Results}

Eighty-five patients were included in the study (see box).

\section{HEALING AND ERADICATION}

Ulcers healed in 74 patients $(87 \%$ ) but failed to heal in 11 (duodenal ulcer, 10; gastric ulcer, 1). Sixty duodenal ulcer patients had healed ulcers $(82 \%)$ compared with nine gastric ulcer patients $(90 \%)$. Seventy-five patients were $H$. pylori-negative after therapy $(88 \%)$ and 10 remained $H$. pylori-positive. Of the 75 patients $H$. pylori-negative after therapy, $69(92 \%)$ had healed ulcers compared with only five of the 10 patients $(50 \%)$ who remained $H$. pylori-positive ( $p=0.003$ ) (figure).

There was no significant difference in age or gender between the $H$. pylori-positive and -negative groups (table 1). Three of the 10 gastric ulcer patients $(30 \%)$ remained $H$. pylori-positive after therapy compared with only seven of the 73 duodenal ulcer patients $(10 \%)(\mathrm{p}=1.0)$. Both patients with combined gastric and duodenal ulcer were $H$. pylorinegative after therapy.

\section{SMOKING, HEALING, AND ERADICATION}

Of the 46 patients who smoked, $38(83 \%)$ had healed ulcers compared with $33(92 \%)$ of the 36 nonsmokers $(p=0.332)$. Thirty-eight of the smokers $(83 \%)$ were $H$. pylori-negative after therapy compared with $34(94 \%)$ of the nonsmokers $(p=0.173)$.

\section{SIDE-EFFECTS AND COMPLIANCE}

Three patients (duodenal ulcer, 2; gastric ulcer, 1) admitted to noncompliance with the treatment regimen. One patient misunderstood the treatment instructions and failed to take the

\begin{tabular}{|l|}
\hline Treatment group -85 patients \\
\hline - 64 male \\
- mean age 47 , range $22-74$ years \\
- 76 smokers \\
- 10 gaodenal ulcers \\
- 2 duodenal and gastric ulcers \\
\hline
\end{tabular}

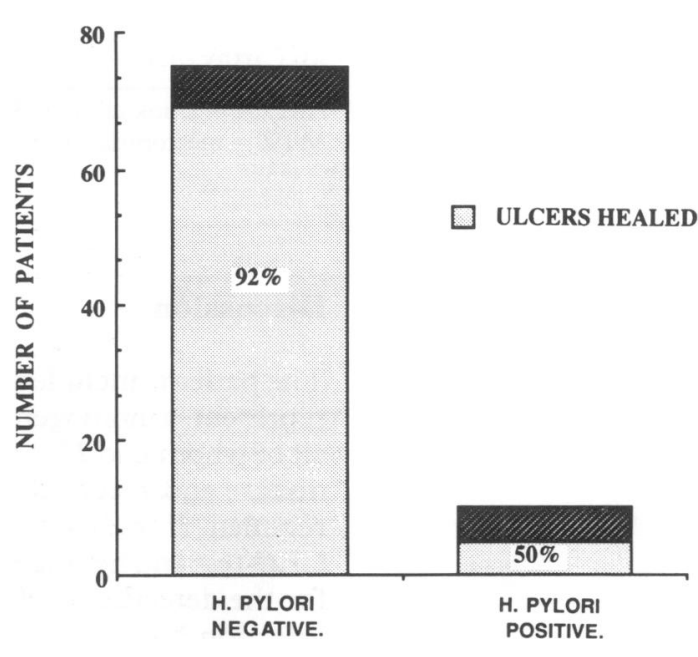

Figure Effect of $H$. pylori eradication on peptic ulcer healing

Table 1 Comparison of the patient groups $H$. pylori-negative and $H$. pylori-positive after therapy

\begin{tabular}{|c|c|c|}
\hline & $\begin{array}{l}\text { H. pylori- } \\
\text { negative }\end{array}$ & $\begin{array}{l}\text { H. pylori- } \\
\text { positive }\end{array}$ \\
\hline Number of patients & 75 & 10 \\
\hline $\begin{array}{l}\text { Mean age (range) } \\
\text { (years) }\end{array}$ & $45(22-74)$ & $37(33-53)$ \\
\hline Male:female & $57: 18$ & $7: 3$ \\
\hline Duodenal ulcer & $66(90 \%)$ & 7 \\
\hline Gastric ulcer & $7(70 \%)$ & 3 \\
\hline $\begin{array}{l}\text { Combined duodenal } \\
\text { and gastric ulcer }\end{array}$ & 2 & - \\
\hline
\end{tabular}

Table 2 Compliance and $H$. pylori eradication

\begin{tabular}{lcc}
\hline & Compliant & Noncompliant \\
\hline$H$. pylori-negative & 75 & 0 \\
$H$. pylori-positive & 7 & 3
\end{tabular}

Fisher's exact test (two-tailed), $\mathrm{p}<0.001$.

antibiotics prescribed for the first week of therapy. Two patients prematurely discontinued antibiotic therapy because of nausea. Two of the three noncompliant patients were cigarette smokers. All three patients remained $H$. pylori-positive after therapy. All of the 75 patients who were $H$. pylori-negative after therapy said they complied with therapy whereas three of the 10 patients who were $H$. pylori-positive after therapy were noncompliant $(\mathrm{p}<0.001)$ (table 2$)$. 
Table 3 Effect of $H$. pylori eradication on peptic ulcer healing, previous studies

\begin{tabular}{|c|c|c|c|c|}
\hline \multirow[b]{2}{*}{ Study } & \multirow[b]{2}{*}{ Therapy } & \multirow{2}{*}{$\begin{array}{l}\text { Patients } \\
\text { (n) }\end{array}$} & \multicolumn{2}{|c|}{ Ulcer healing (\%) } \\
\hline & & & $H P$-positive & HP-negative \\
\hline Marshall et $a l^{7}$ & $\begin{array}{l}\text { CBS vs CBS + TIN } \\
\text { vs CIM vs CIM + TIN }\end{array}$ & 100 & 61 & 92 \\
\hline Graham $e t a l^{8}$ & $\begin{array}{l}\text { RAN vs RAN + AMOX } \\
+ \text { TET + MTZ }\end{array}$ & 105 & 84 & 98 \\
\hline Hentschel et $a l^{9}$ & $\begin{array}{l}\text { RAN vs RAN + AMOX } \\
+ \text { MTZ }\end{array}$ & 104 & 75 & 92 \\
\hline Hosking et al ${ }^{10}$ & $\begin{array}{l}\text { OM vs OM + CBS + TET } \\
+ \text { MTZ }\end{array}$ & 155 & 78 & 95 \\
\hline McCarthy et al ${ }^{11}$ & $\mathrm{OM}+\mathrm{MTZ}+\mathrm{TET}$ & 43 & 34 & 66 \\
\hline
\end{tabular}

AMOX = amoxicillin; CBS = colloidal bismuth subcitrate; $\mathrm{CIM}=$ cimetidine; $\mathrm{HP}=H$. pylori;

$\mathrm{MTZ}=$ metronidazole; $\mathrm{OM}=$ omeprazole; $\mathrm{RAN}=$ ranitidine; $\mathrm{TET}=$ tetracycline; $\mathrm{TIN}=$ tinidazole

\section{Discussion}

The patients included in this prospective study represent a homogeneous consecutive group, all of whom had $H$. pylori-positive peptic ulcer disease and received a standard triple therapy regimen. $H$. pylori status was assessed using the CLO test and histology, both accurate methods for the detection of the presence or absence of infection. ${ }^{6}$

The principal finding was that patients $H$. pylori-negative after therapy had significantly more healed ulcers than patients who remained $H$. pylori-positive $(92 \%$ vs $50 \%)$. This finding is in accord with data already available on the effects of $H$. pylori eradication on peptic ulcer healing (table 3).$^{7-11}$ The beneficial effect of $H$. pylori eradication on ulcer healing was evident for both duodenal and gastric ulcer. The mucosal damage and inflammatory response which accompany $H$. pylori infection regress quickly after eradication of infection. ${ }^{12}$ Rapid restoration of mucosal integrity may explain how eradication of $H$. pylori could facilitate the ulcer-healing process.

This study also afforded the opportunity to assess patient factors which might influence $H$. pylori eradication. Age and gender had no apparent effect on eradication but it is of interest that $30 \%$ of gastric ulcer patients remained $H$. pylor $i$-positive after therapy compared with only $10 \%$ of duodenal ulcer patients. Cutler and Schubert, ${ }^{13}$ using a triple therapy regimen, reported a $64 \%$ eradication rate in gastric ulcer compared with $91 \%$ in duodenal ulcer patients. About $70 \%$ of gastric ulcers are $H$. pylori-positive compared with over $90 \%$ of duodenal ulcers ${ }^{14}$ but differences in virulence ${ }^{15}$ or antibiotic sensitivity ${ }^{16}$ have not been detected between $H$. pylori strains isolated from gastric and duodenal ulcer patients. It is possible that differences in the intragastric milieu between gastric and duodenal ulcer patients might influence the helicobactericidal efficacy of treatment regimens. ${ }^{17}$

Cigarette smoking is more common in patients with peptic ulcer disease than in nonulcer controls. ${ }^{18}$ Fifty-four per cent of our patients were regular cigarette smokers compared with a reported population prevalence of $27 \% .{ }^{19} \mathrm{We}$ found that cigarette smoking had no significant effect on ulcer healing but cigarette

\section{Summary points}

- more healed ulcers were found in patients rendered $H$. pylori-negative after triple therapy

- cigarette smokers have a lower $H$. pylori eradication rate than non-smokers

smokers had a lower $H$. pylori eradication rate than nonsmokers $(83 \%$ vs $94 \%$ ). Cutler and Schubert ${ }^{13}$ reported a similar finding, while Unge et $a l^{20}$ found that smoking also had a significant adverse effect on $H$. pylori eradication in patients treated with omeprazole and amoxacillin. Witteman et $a l^{21}$ have reported that $H$. pylori in smokers acquire secondary metronidazole resistance more readily than $H$. pylori in nonsmokers. This novel finding might explain why $H$. pylori eradication therapy seems less effective in smokers than nonsmokers.

Although efficacious, triple therapy is a cumbersome multidrug regimen which does not encourage good compliance. That only three of our patients $(4 \%)$ admitted to noncompliance may reflect the time and care spent counselling patients about the importance of compliance and the side-effects to expect with triple therapy. Our results, however, reiterate the critical relationship between noncompliance and treatment failure. ${ }^{22}$ All three noncompliant patients remained $H$. pylori-positive after therapy whereas good compliance was associated with successful eradication and ulcer healing.

It is now firmly established that $H$. pylori eradication prevents peptic ulcer relapse, altering the natural history of the disease. ${ }^{23}$ The fact that $H$. pylori eradication also accelerates ulcer healing adds further weight to the conclusion that an effective helicobactericidal regimen is the treatment of choice in $H$. pylori-positive peptic ulcer disease.

Sincere thanks are due to the Nursing Staff of the Endoscopy Unit, General Hospital, Tullamore, and to Mrs Iris Martin for typing the manuscript. 
1 Coghlan JG, Gilligan D, Humphries H, et al. Campylobacter pylori and recurrence of duodenal ulcers - a 12 -month pylori and recurrence of duodenal ulcers

2 Rauws EAJ, Tytgat GNJ. Cure of duodenal ulcer associated with eradication of Helicobacter pylori. Lancet 1990; 335 1233-5

3 George LL, Borody TJ, Andrews P, et al. Cure of duodenal ulcer after eradication of Helicobacter pylori. Med $\mathcal{F}$ Aust 1990; 153: 145-9.

4 Graham DY, Lew GM, Klein PD, et al. Effect of treatment of Helicobacter pylori infection on the long-term recurrence of gastric or duodenal ulcer: a randomized, controlled study. Ann Intern Med 1992; 116: 705-8.

5 Marshall BJ, Warren JR, Francis GJ, Langton SR, Goodwin CS, Blincow ED. Rapid urease test in the management of Campylobacter pyloridis-associated gastritis. Am $\mathcal{f}$ Gastroenterol 1987; 82: 200-10.

6 Brown KE, Peura DA. Diagnosis of Helicobacter pylori infection. Gastroenterol Clin N Am 1993; 22: 105-15.

7 Marshall BJ, Goodwin CS, Warren JR, et al. Prospective double-blind trial of duodenal ulcer relapse after eradication of Campylobacter pylori. Lancet 1988; 2: 1437-42.

8 Graham DY, Lew GM, Evans DG, Evans DJ Jr, Klein PD. Effect of triple therapy (antibiotics plus bismuth) on duodenal ulcer healing with ranitidine. Ann Intern Med 1991; 115: 266-9.

9 Hentschel E, Brandstatter G, Dragosics B, et al. Effect of ranitidine and amoxicillin plus metronidazole on the eradication of Helicobacter pylori and the recurrence of duodenal ulcer. $N$ Engl f Med 1993; 328: 308-12.

10 Hosking SW, Ling TKW, Yung MY, et al. Randomised controlled trial of short-term treatment to eradicate Helicobacter pylori in patients with duodenal ulcer. $B M \mathcal{F}$ 1992; 305: 502-4.

11 McCarthy CJ, Collins R, Beattie S, Hamilton H, O'Morain C. Short report: treatment of Helicobacter pylori-associated duodenal ulcer with omeprazole plus antibiotics. Aliment Pharmacol Ther 1993; 7: 463-6.
12 Rauws EAJ, Langenberg W, Houthoff $\mathrm{HJ}$, Zanen $\mathrm{HC}$ Tytgat GNJ. Campylobacter pyloridis-associated chronic Tytgat GNJ. Campylobacter pyloridis-associated chronic active antral gastritis: a prospective study of its prevalence
and the effects of antibacterial and antiulcer treatment. and the effects of antibacterial and

13 Cutler AF, Schubert TT. Patient factors affecting Helicobacter pylori eradication with triple therapy. Am $\mathcal{F}$ Gastroenterol 1993; 88: 505-9.

14 O'Connor HJ, Dixon MF, Wyatt JI, Axon ATR, Dewar EP, Johnston D. Campylobacter pylori and peptic ulcer disease. Lancet 1987; 2: 633-4.

15 Crabtree JE, Taylor JD, Wyatt JI, et al. Mucosal IgA recognition of Helicobacter pylori $120 \mathrm{kDa}$ protein, peptic ulceration, and gastric pathology. Lancet 1991; 338: 332-5.

16 Xia HX, Daw MA, Beattie S, Keane CT, O'Morain CA. Prevalence of metronidazole-resistant Helicobacter pylori in dyspeptic patients. Ir $\mathcal{F}$ Med Sci 1993; 162: 91-4.

17 Lee A. $H$. pylori-initiated ulcerogenesis: look to the host. Lancet 1993; 341: 280-1.

18 Kikendall JW, Evaul J, Johnson LF. Effect of cigarette smoking on gastrointestinal physiology and non-neoplastic digestive disease. $¥$ Clin Gastroenterol 1984; 6: 65-79.

19 Shelley E, Daly L, Kilcoyne D, Graham I, Mulcahy R. Risk factors for coronary heart disease: a population survey in County Kilkenny, Ireland, in 1985. Ir ₹ Med Sci 1991; 160 (suppl 9): 22-8.

20 Unge P, Gad A, Eriksson K, et al. Amoxacillin added to omeprazole prevents relapse in the treatment of duodenal ulcer patients. Eur f Gastroenterol Hepatol 1993; 5: 325-31.

21 Witteman EM, Hopman WPM, Becx MCJM, et al. Short report: smoking habits and the acquisition of metronidazole resistance in patients with Helicobacter pylori-related gastritis. Aliment Pharmacol Ther 1993; 7: 683-7.

22 Graham DY, Lew GM, Malaty HM, et al. Factors influencing the eradication of Helicobacter pylori with triple therapy. Gastroenterology 1992; 102: 493-6.

23 O'Connor HJ. Eradication of Helicobacter pylori: therapies and clinical implications. Postgrad Med f 1992; 68: 549-57. 